\title{
Do We Observe While Learning and Teaching?
}

he most pivotal aspect of any research paper or publication is the set of inferences that are derived from the observations. A researcher does careful planning so as to avoid all possible biases in the experiment, so that the observations and the inferences will have their internal and external validity. While, in the field of research, we strive towards the phenomenon of observation, we fail to extrapolate the same towards the everyday observation in our social and academic life. Is it imperative to think about observations, observational learning and teaching methodologies? Academicians in the field of psychology and education investigate curiously this phenomenon of observational learning. Observational learning is one of the most powerful aids to knowledge, the most intricate learning mechanism of mankind.

Albert Bandura, a Canadian born psychologist, in his classical Bobo doll experiment in 1961 and 1963 revealed the power and influence of observational learning in children ${ }^{(1)}$. The Bobo doll is a soft inflatable five foot plastic doll with a round base similar to that of an egg. When hit or kicked by the hammer, it falls and lifts itself up immediately, similar to traditional Indian "Tanjore Dolls". In brief, the experiment consisted of two groups of children who were allowed to observe the adults treating the dolls. One group of children was observing the adult's aggressive behavior towards the doll, through the form of physical assaults and verbal abuse. Another group of children was exposed to no such aggressive behavior. Children exposed to the aggressive behavior of adults, treated the bobo doll similarly, in an aggressive way. And the group which was not exposed to aggressiveness and abuse, their treatment towards the dolls were devoid of such reactions. By this he proved that social behavior is influenced by observation and it could be a powerful tool towards constructive or destructive behavior. Learning through mere observations has the fruit of long lasting retention. The different stages of observational learning are beyond the scope of this discussion.

Another commonly used historical incident can be taken as example for the power of observational learning. That is the interpretation between Planck knowledge $V_{s}$ "Chauffeur knowledge"(2). Max Planck, Nobel Prize winner from Germany, travelled across Germany and Europe to deliver his lecture on his noble prize winning theory. He was delivering the same lecture everywhere and his chauffeur was touring along with him. His chauffeur, with keen observation, was confident enough to deliver the same lecture; he had asked Planck whether he 
can deliver it instead of him. When Planck accepted, the chauffeur delivered the lecture in Munich in the midst of an academic crowd, and almost stole the show! But alas, he was not Planck, and, when asked a rather difficult question, he failed to answer. While this story often relates the "Chauffeur knowledge" to "half baked knowledge", it can also be related to the power of observation. Hence it is imperative for all learners, from students to researchers, to cultivate a habit of keen observation. Having cultivated it, learning becomes a very joyful process.

The attempt of the teachers to truly understand observational learning and incorporate it in their teaching methodology is an assiduous task. A teacher, who has understood the value and means of achieving this comprehension, will inevitably excel in the field of teaching. The Western teaching models and modalities do not consider this as a separate entity and state that all teachers are the same. A teacher is defined as a person who teaches a subject in the best possible way, as stated by the education system. To arrive at a more fuller comprehension, The Vedic literature will help us, by providing a clear definition of the responsibility of the teacher and the role of observational teaching and learning. According to the Vedic literature, the person who teaches any art or subject can be a Shikshak, Acharya or Guru ${ }^{(3)}$. The "Shikshak" is the literal translation for a teacher as per norms of the western models. He is a teacher, instructor, who teaches from the knowledge of Shastras (books and other mediums). But "Acharaya", is the next level of teacher. He shows, lives by example and encourages observational teaching for the students to learn. Whereas the "Guru" gives the student a direct experience; not only by observational teaching, but by opening the student's mind to the fundamental essence of whatever knowledge they may pursue. Consequentially, the experience of learning will become joyous and simple in its very nature.

Thus since the Vedic times, it has been stressed time and again that the power of observation is exceedingly rewarding for both the teacher as well as the student; and once made firm in our academic methodologies, teaching and learning will inevitably transform from being a challenging experience to being a simply blissful experience. I am sure that all observant readers have grasped the essential message of this article. If not mail me at jsdigids@gmail.com.

\section{REFERENCES:}

1. Bandura, A. Ross, Dorothea; Ross, Sheila A. Transmission of aggression through imitation of aggressive models. The Journal of Abnormal and Social Psychology, Vol 63(3), Nov 1961, 575-582.

2. Grey Speicher. Planck Knowledge Vs Chauffeur knowledge [internet].[Place unknown]: [updated 2011 jan 11]. Available from: http://gregspeicher.com/?p=1982

3. Sraddhalu Ranade. 'The Indian Genius [internet].[IIT, chennai]: [March 31-April 2, 2012. updated 2013 March 13]. Available from: http://www.vsc.iitm.ac.in/Home/?page_id=511

How to cite this article:

Sathyanarayanan R. Do We Observe While Learning and Teaching? Journal of Scientific Dentistry $2014 ; 4(2): 1-2$ 